\title{
BIOESTRATIGRAFIA BASEADA EM FORAMINÍFEROS DO SOPÉ CONTINENTAL DO LITORAL NORTE DO ESTADO DA BAHIA, BRASIL
}

\author{
Adelino da Silva RIBEIRO NETO \\ Tânia Maria Fonseca ARAÚJO \\ Helisângela Acris Borges de ARAÚJO
}

\begin{abstract}
RESUMO
O período Quaternário é caracterizado por grandes mudanças climáticas, amplamente registradas nas bacias oceânicas devido à sedimentação contínua e lenta. Considerando esta condição, o presente trabalho analisa a distribuição vertical da microfauna de foraminíferos ao longo do testemunho REG-114, coletado no sopé do assoalho oceânico ao largo do litoral norte do Estado da Bahia, e apresenta os resultados de análises bioestratigráficas a partir do estudo das assembleias desses organismos. O referido testemunho foi coletado na profundidade de $2.640 \mathrm{~m}$ em 2008. Em laboratório, foi possível extrair oito amostras, em intervalos de $20 \mathrm{~cm}$, que foram tratadas segundo metodologia padrão para sedimentos carbonáticos. Em todas as amostras a fração mais abundante foi argila (>75\%). Ao longo da coluna sedimentar foram identificadas 63 espécies de foraminíferos, distribuídas em 35 gêneros, sendo 28 bentônicas e 7 planctônicas. As principais espécies encontradas foram: Globigerinoides ruber (43,96\%), G. trilobus (11,42\%), G. elongatus (11,33\%), Globigerina bulloides (6,58\%), Globigerinoides saculifer (6,04\%) e Globorotalia trucatulinoides (5,21\%). De acordo com as flutuações das espécies planctônicas foi possível identificar duas Zonas bioestratigráficas (Zonas Y e Z) e duas Subzonas (Subzonas Y2 e Y1). O limite entre estas subzonas foi estabelecido pelo decréscimo das espécies Globorotalia trucatulinoides e G. crassaformis, características de água fria, e o aumento da espécie Globigerinoides saculifer, típica de água quente, indicando o aquecimento abrupto da massa d'água. Associado a isso, a distribuição de espécies planctônicas, com porcentagens $>90 \%$, indica que não houve remobilização de sedimentos no fundo oceânico, confirmando a estabilidade ambiental nesta região, caracterizada por baixo aporte sedimentar.
\end{abstract}

Palavras-chave: Quaternário, sopé continental, foraminíferos, bioestratigrafia.

\section{ABSTRACT}

The Quaternary period is characterized by environmental changes, widely recorded in the ocean basins due to continuous, slow sedimentation. Considering this condition, this paper analyzes the vertical distribution of the foraminiferal microfauna in core REG-114, collected at the foot of the continental rise off the north coast of Bahia, and presents the results of biostratigraphic analysis of fossil assemblages of these organisms. The core was collected at a depth of 2,640 $\mathrm{m}$ in 2008. In the laboratory, eight samples extracted at intervals of $20 \mathrm{~cm}$ were treated according to the standard methodology for carbonate sediments. In all samples the most abundant fraction was clay $(>75 \%)$. Along the sedimentary column 63 species of foraminifera, belonging to 35 genera, 28 benthic and 7 planktonic, were identified. The main species found were: Globigerinoides ruber (43.96\%), G. trilobus (11.42\%), G. elongatus $(11.33 \%)$ Globigerina bulloides (6.58\%), Globigerinoides saculifer (6.04\%) and Globorotalia trucatulinoides (5.21\%). On the basis of fluctuations in the planktonic species, it was possible to identify two biostratigraphic zones (Zones $\mathrm{Y}$ and $\mathrm{Z}$ ) and two subzones (Y1 and Y2). The boundary between these subzones was established by the decline of the 
species Globorotalia trucatulinoides and G. crassaformis, characteristic of cold water, and an increase in Globigerinoides saculifer, characteristic of warm water, indicating abrupt warming of the water mass. Associated with this, the distribution of planktonic species, with percentages $>90 \%$, indicates that sediments were not remobilized on the ocean floor, thus confirming the environmental stability in this region, as characterized by the low sediment supply.

Keywords: Quaternary, continental rise, foraminifera, biostratigraphy.

\section{INTRODUÇÃO}

A margem continental brasileira foi influenciada por grandes mudanças climáticas e variações do nível do mar, principalmente no período Quaternário (MARTIN et al 1980). Este período abrange, aproximadamente, os últimos 2,6 Ma da história geológica da Terra e se subdivide em duas épocas: o Pleistoceno (entre 2,6 e 0,01 Ma) e Holoceno $(0,01 \mathrm{Ma}$ ao Recente).

O efeito destas mudanças climáticas durante o Quaternário refletiu-se de forma diferenciada no planeta, representado por maior ou menor umidade ou por mudanças de temperatura. O registro sedimentar das glaciações quaternárias nos continentes ainda é incompleto, ao contrário do que ocorre nas bacias oceânicas. A sedimentação lenta e contínua no fundo oceânico, associada com microrganismos como os foraminíferos (ERICSON \& WOLLIN 1968; VICALVI 1999), tornam esses registros sedimentares adequados para o reconhecimento das mudanças paleoclimáticas no Quaternário.

Os foraminíferos atualmente são classificados no Reino Protoctista, Filo Granuloreticulosa, Classe Foraminifera (SEN GUPTA 1999). São formados por testas calcárias, compostas por minerais de carbonato de cálcio, ou aglutinantes, constituídas por grãos de areia, fragmentos calcários ou espículas de esponja, com formatos que variam de acordo com o seu hábito bentônico ou planctônico (CORLISS \& FOIS 1990, BOLTOVSKOY et al. 1991). Ainda existem foraminíferos que desenvolvem testas orgânicas no fundo marinho (GOODAY 2002, PAWLOWSKI et al. 2002).

A testa é uma estrutura essencial para os foraminíferos, que lhes conferem vantagens como a proteção contra predadores e condições físicas ou químicas desfavoráveis, além de auxiliar na reprodução e no controle da flutuabilidade desses organismos (BOLTOVSKOY et al. 1991).

Os foraminíferos possuem uma grande distribuição em ambientes marinhos, onde podem ser encontrados desde as zonas sublitorâneas até a zona abissal, bem como em lagoas e estuários de águas salobras (DENNE \& SEN GUPTA 1991). Assim, esses organismos são importantes nos estudos ambientais por possuírem alta sensibilidade a fatores bióticos ou abióticos (temperatura, salinidade, profundidade, poluição, turbidez, entre outros), que influenciam em sua distribuição e morfologia. A ecologia e a distribuição dos foraminíferos têm sido correlacionadas a estudos de componentes, transporte e produção de sedimentos (ARAÚJO \& MACHADO 2008).

Do ponto de vista geológico, esses organismos são importantes porque suas testas passam a compor os sedimentos quando morrem ou se reproduzem (UFKES et al. 2000). Essas testas irão constituir os sedimentos do fundo marinho, que podem ser transportados ou erodidos.

O objetivo deste trabalho é analisar o padrão de distribuição vertical da microfauna de foraminíferos do testemunho REG-114, coletado no sopé do assoalho oceânico do litoral norte do Estado da Bahia, com o intuito de identificar zonas bioestratigráficas, a partir do estudo das assembleias desses organismos.

\section{2 ÁREA DE ESTUDO}

O testemunho REG-114 (coordenadas UTM de 633.725/8.615.701 a 643.849/8.609.171) foi coletado à profundidade de $2.640 \mathrm{~m}$, no sopé continental do distrito de Imbassaí (Município de Mata de São João), no litoral norte do Estado da Bahia, distando $10 \mathrm{~km}$ da linha da costa (Figura 1).

2.1 Caracterização da plataforma e do sopé continental

A plataforma brasileira foi segmentada em setores pelo projeto REMAC (Reconhecimentos Global da Margem Continental Brasileira), que classificou esta área como margem continental leste brasileira. 


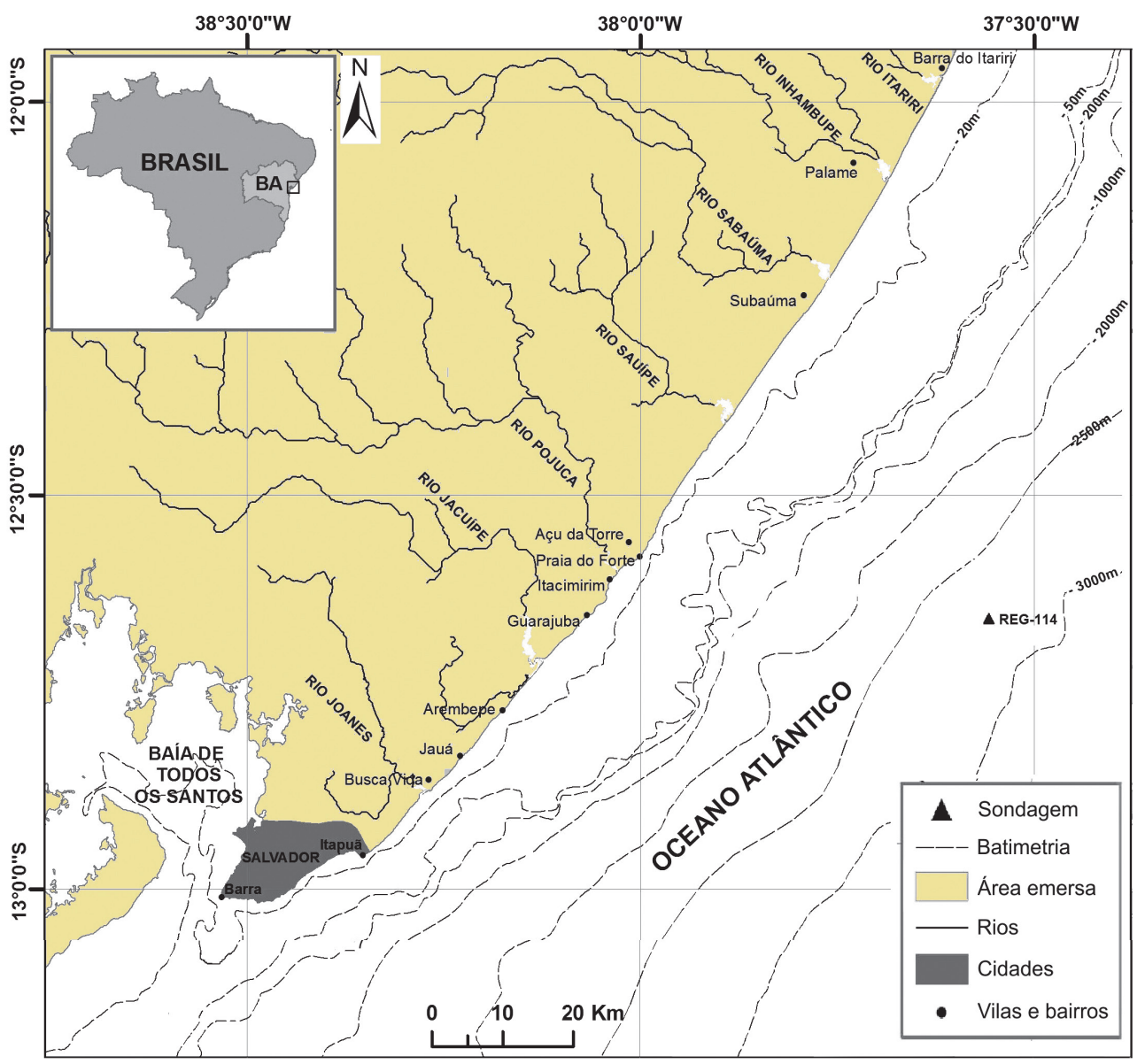

FIGURA 1 - Mapa de localização da área de estudo e do local de coleta do testemunho REG 114.

Na parte norte do Estado da Bahia (ao norte de Salvador), a plataforma continental possui largura média de $20 \mathrm{~km}$, enquanto a mínima é de 8 $\mathrm{km}$ em frente à cidade de Salvador. Apresenta declividades acentuadas: 1:80 (entre a linha de costa e a isóbata de $10 \mathrm{~m}$ ), 1:300 (entre as isóbatas de 10 e $30 \mathrm{~m}$ ) e 1:570 (entre as isóbatas de 30 e $50 \mathrm{~m}$ ) (SUGUIO 1992). A borda da plataforma localiza-se entre as isóbatas de 60 e $80 \mathrm{~m}$, distante, aproximadamente, $18 \mathrm{~km}$ da linha de costa.

O sopé continental é a superfície submarina mais externa da margem continental e localiza-se entre a base do talude continental e as planícies abissais. O sopé continental possui largura entre 100 a $1.000 \mathrm{~km}$, profundidade entre 1.300 a 4.000 m e gradientes suaves, menores que 1:1000 (ZEMBRUSCKI 1979, MAIA 2013). O limite externo é delimitado por gradientes maiores que 1:1.000. O sopé continental distingui-se pelo relevo de desníveis locais menores que $100 \mathrm{~m}$, formado por colinas baixas na porção superior, e uma porção inferior horizontal, com relevo plano à suavemente ondulado, o que sugere processos de sedimentação por deslizamento e desmoronamento na região proximal e de correntes de turbidez e erosão-deposição por correntes de fundo na porção inferior (PALMA 1984, ALVES 1999).

\section{MATERIAIS E MÉTODOS}

A Agência Nacional do Petróleo executou, em 2008, uma campanha de sondagens para coletar testemunhos verticais ao longo da margem continental do litoral norte do Estado da Bahia, que foram armazenados no Laboratório de Estudos Costeiros (LEC) do Instituto de Geociências da Universidade Federal da Bahia. Selecionou-se um desses testemunhos, coletado no sopé continental, para o presente estudo.

O testemunho foi seccionado longitudinalmente para exposição da coluna sedimentar e por cortes transversais, em intervalos de $20 \mathrm{~cm}$, para retirada de oito amostras. As amostras de sedimen- 
tos foram armazenadas em placas de Petri, rotuladas com seus respectivos números, pesos e, em seguida, foram secas em estufa a temperatura de $45^{\circ} \mathrm{C}$.

As amostras selecionadas para estudo da granulometria e microfauna de foraminíferos foram lavadas com água corrente sobre uma peneira com malha de $0,062 \mathrm{~mm}$ a fim de eliminar os sais e, novamente, postas para secar a uma temperatura de $45^{\circ} \mathrm{C}$.

A malha de $0,062 \mathrm{~mm}$ da peneira também permite eliminar o silte e a argila da amostra, sem perda de parcela significativa da população jovem de foraminíferos (SCHRÖDER et al. 1987). Segundo SCOTT et al. (2001), o uso de malhas superiores a $0,125 \mathrm{~mm}$ pode promover a perda de $99 \%$ dos indivíduos, uma vez que muitas espécies bentônicas possuem tamanho entre 0,03 e $0,062 \mathrm{~mm}$ (FARIDUDDIN \& LOUBERE 1997, DIZ \& FRANCÉS 2008). Em vista disso, inúmeros trabalhos realizados no Brasil adotaram essa metodologia, confirmando sua eficácia (JOHNSSON 1999, VIEIRA 2011).

Posteriormente, as amostras foram pesadas e desagregadas para determinação da fração lamosa (silte e argila). As amostras secas passaram por quarteamento e foram triadas as 300 primeiras testas inteiras, utilizando-se microscópio estereoscópico alocado no Laboratório do Grupo de Estudos de Foraminíferos (GEF/ UFBA), seguindo a metodologia proposta por TINOCO (1984). As testas selecionadas foram dispostas em lâminas de fundo preto para classificação.

A identificação das testas de foraminíferos teve como base a utilização dos trabalhos especializados no estudo desses organismos, sobretudo aqueles realizados na costa da Bahia, como os de TINOCO (1984), NASCIMENTO (2003), ARAÚJO (2004), dentre outros. A análise dos dados baseou-se nas frequências de ocorrência e abundância relativa das espécies.

A abundância relativa (AR) representa o número total de indivíduos de todas as espécies da amostra (T), expresso em percentagem, e é calculado a partir da fórmula: $A R=n \times 100 / T$. O resultado permitiu classificar as espécies em: principais (presentes em mais de 5\% das amostras), acidentais (presentes entre $1 \%$ e $4,9 \%$ das amostras) e traços (presentes em menos de 1\% da amostra), de acordo com os critérios de DAJOZ (1983).

A frequência de ocorrência (FO) é expressa pela relação entre o número de amostras onde a espécie ocorre $(\mathrm{p})$ e o número total de amostras analisadas (P) (TINOCO 1984), calculada pela fórmula: $\mathrm{FO}=\mathrm{p} \times 100 / \mathrm{P}$. Os resultados dessa análise também foram agrupados, segundo critérios de DAJOZ (1983), nas seguintes categorias: espécies constantes (presentes em mais de 50\% das amostras), espécies acessórias (presentes em 25\% a 50\% das amostras) e espécies acidentais (presentes em menos de $25 \%$ das amostras).

Considerando o elevado número de espécies identificadas, a análise de agrupamento envolveu apenas os indivíduos constantes, ou seja, as espécies que possuem frequência de ocorrência maior que $50 \%$ e os indivíduos principais e acessórios, ou seja, com frequência relativa maior que $1 \%$.

Para a análise da razão Planctônico/Bentônico foi utilizada a relação entre os foraminíferos de hábito bentônico e planctônico encontrados em cada amostra.

\section{RESULTADOS E DISCUSSÕES}

O testemunho REG 114 possui comprimento total de $1,35 \mathrm{~m}$, do qual recuperou-se $1,30 \mathrm{~m}$ para esse estudo. Os sedimentos apresentam coloração amarela escuro, sem estruturas sedimentares ou variações granulométricas visíveis macroscopicamente. A composição é predominantemente de argila (teor $>$ $75 \%$ ), com teores crescentes para a base do testemunho (amostra 14). Esta característica já era esperada, uma vez que o testemunho foi coletado distante da costa, onde não há influência do aporte de sedimentos arenosos provenientes da descarga dos rios Sauípe e Imbassaí, ou seja, o ambiente de coleta possui baixa hidrodinâmica e turbidez, o que resulta em grandes quantidades de sedimentos lamosos.

A análise dos foraminíferos revelou 63 espécies, distribuídas em 35 gêneros ( 28 bentônicas e 7 planctônicas), de um total de 2.400 testas. A ordem Globerinina é a mais abundante (23 espécies), seguida da ordem Miliolina (14 espécies).

O cálculo da frequência de ocorrência identificou um alto percentual de espécies acessórias (41,1\%). Apesar de estarem em um ambiente de baixa energia de fundo, o fato das espécies apresentarem frequências relativamente baixas pode estar relacionado à presença de testas frágeis de espécies bentônicas calcárias hialinas e planctônicas, como identificado por RIBEIRO NETO (2012) na costa sul do Estado da Bahia e por ARAÚJO \& MACHADO (2008) e PIANNA (2010) no litoral norte do mesmo estado.

Dentre os foraminíferos identificados, os mais abundantes (principais) são: Globigerinoides ruber f. typica $(43,96 \%)$, G. trilobus $(11,42 \%), G$. elongatus (11,25\%), Globigerina bulloides (6,5\%), Globigerinoides saculifer (6,04\%) e Globorotalia trucatulinoides $(5,21 \%)$.

Estes resultados, associados com o predomínio de sedimentos lamosos, estão relacionados com a baixa hidrodinâmica do ambiente, que também evidencia baixa turbidez e profundidade, como identificado em outros trabalhos da região 
(ARAÚJO \& MACHADO 2008, PIANNA 2010, DREFHAL 2011).

É possível constatar a alta salinidade e temperatura em torno de $20^{\circ} \mathrm{C}$ da água superficial, uma vez que a associação das espécies principais coexistem nesta faixa de temperatura, como a presença da espécie Globorinoides ruber (d'ORBIGNY 1826, DREFHAL 2011).

A falta de espécies dos plexos Pulliatina e Globorotalia menardii, bioindicadoras de águas quentes (ERICSSON \& WOLIN 1968, VICALVI 1999), impossibilita a marcação precisa dos limites bioestratigráficos.

Ao longo de todo o testemunho, foram identificados 312 espécimes de água fria (ERICSSON \& WOLIN 1968, VICALVI 1999, ARAÚJO 2004), distribuídas entre as espécies Globigerina bulloides, Globorotalia crassaformis e G. trucatulinoides e 1209 espécimes de água quente (ERICSSON \& WOLIN 1968, VICALVI 1999, ARAÚJO 2004), relacionadas às espécies Globigerinoides ruber e G. saculifer. Só foram encontrados dois exemplares do plexo Globorotalia menardii.
Assim, foi possível identificar as zonas Y (Pleistoceno) e Z (Holoceno), sugeridas por ERICSSON \& WOLIN (1968), e as subzonas Y2 e Y1, que são divisões do período Pleistoceno propostas por VICALVI (1999). Não foram identificadas as Subzonas Y1B e Y1A, sugeridas por KOWSMANN \& VICALVI (2003).

$$
\text { - Zona Y (1,30 m à 0,01 m) }
$$

Esta zona compreende todo o testemunho e é caracterizada pela maior frequência de Globigerinoides ruber (36\% a 50,67\%), pelo decréscimo de Globorotalia trucatulinoides em direção ao topo $(2,33 \%$ a $8,33 \%)$ e maior abundância de G. crassaformis $(1,33 \%$ a $2 \%)$.

A tendência de diminuição das espécies Globorotalia trucatulinoides e G. crassaformis para o limite da zona são as principais características da Zona Y (VICALVI 1999, SANJINÉS 2006) (Figura 2). Esta zona pode ser dividida em duas subzonas: Y2 e Y1, propostas por VICALVI (1999).

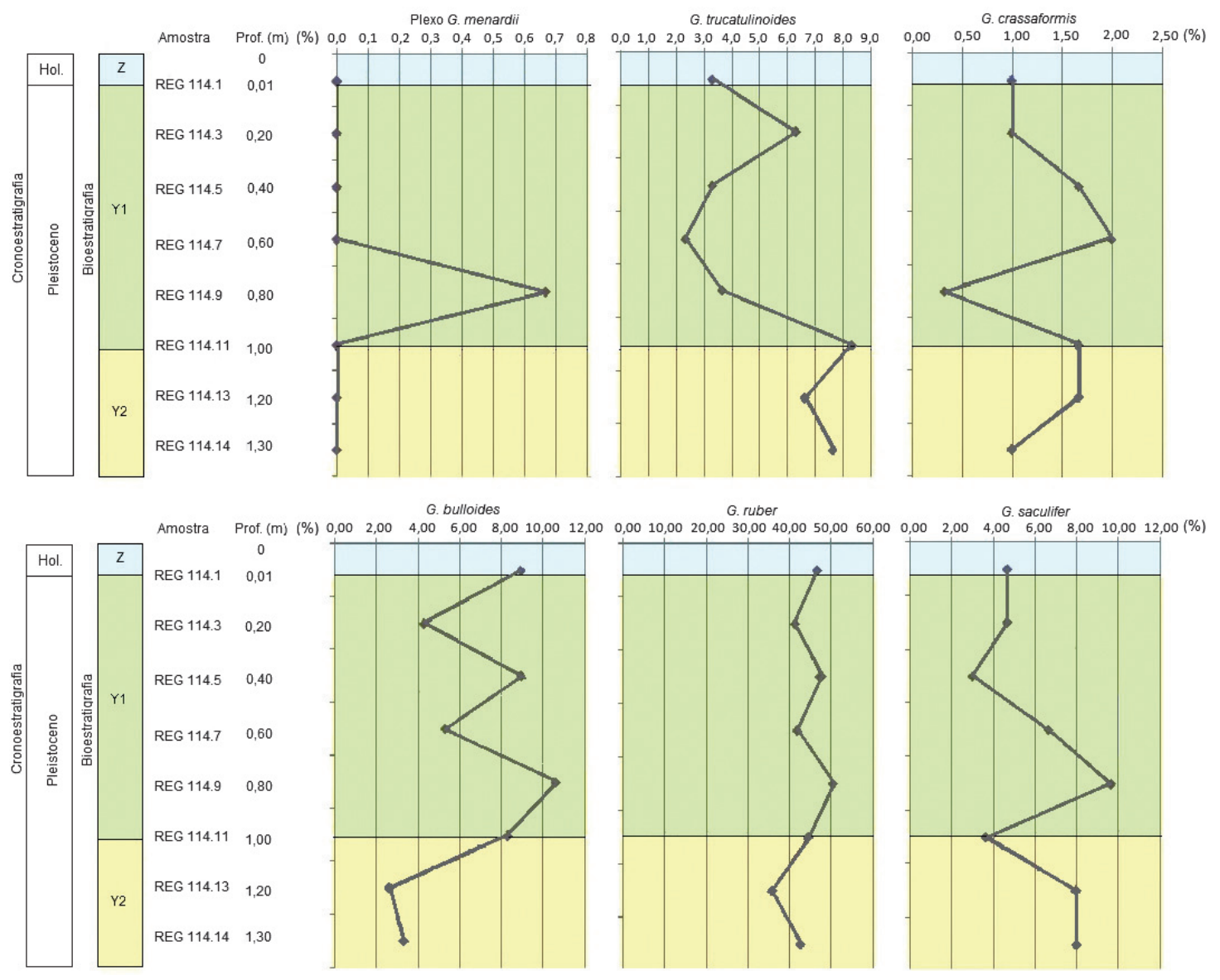

FIGURA 2 - Distribuição das espécies planctônicas utilizadas no biozoneamento do testemunho REG 114. 
- Subzona Y2 (1,30 m à 1,00 m)

É caracterizada pelos maiores índices de Globorotalia trucatulinoides ( $6,67 \%$ a $8,33 \%$ ) e de $G$. crassaformis ( $1 \%$ a $1,67 \%)$ e a menor frequência de Globigerinoides ruber (36\% a 44,67\%) ao longo do testemunho. Observa-se, ainda, a presença de Globigerina bulloides $(2,67 \%$ a $8,33 \%$ ) e Globigerinoides saculifer (3,67\% a $8 \%$ ); os plexos Globorotalia menardii e Pulleniatina estão ausentes (Figura 2).

$\mathrm{O}$ pico de maior frequência das espécies Globorotalia trucatulinoides e G. crassaformis e o menor registro de Globigerinoides saculifer é constatado em 1,00 m e marca o limite desta subzona.

- Subzona Y1 (1,00 m à 0,01 m)

Esta subzona é marcada pela diminuição da frequência de Globorotalia trucatulinoides (2,33\% a 6,33\%), com seu menor registro na amostra 07 ( $0,60 \mathrm{~m}$ de profundidade), seguido de um aumento brusco no topo do intervalo (amostra 03, com $0,20 \mathrm{~m}$ de profundidade). Observa-se também a diminuição da frequência da espécie Globorotalia crassaformis $(0,33 \%$ a $2 \%)$ e um aumento abrupto de Globigerinoides saculifer (3\% a 9,67\%) a partir da amostra 09 ( $0,80 \mathrm{~m}$ de profundidade). O comportamento destas três espécies indica um aquecimento rápido na massa de água, seguido por um resfriamento das águas da superfície do mar. Tais condições ambientais prevalecem no intervalo de tempo compreendido entre 42 a 11 mil anos, uma vez que há uma inversão no padrão de distribuição das mesmas. Este padrão é corroborado pela presença do plexo Globorotalia menardii $(0,67 \%)$ na amostra 09 , mesmo que em pouca quantidade.

Nesta subzona ainda se observa um pequeno aumento de Globigerina bulloides $(4,33 \%$ a $10,67 \%)$ e de Globigerinoides ruber $(41,33 \%$ a $50,67 \%$ ) e a ausência do plexo Pulleniatina (Figura 2).

\section{- Zona Z (0,01 $\mathrm{m}$ ao topo)}

Ao contrário do observado nos trabalhos de ERICSSON \& WOLIN (1968), VICALVI (1999), ARAÚJO (2004) e SANJINÉS (2006), esta zona é marcada pela ausência do plexo Globorotalia menardii e pela ausência relativa do plexo Pulleniatina $(0,33 \%)$. Há uma queda na frequência de Globorotalia trucatulinoides $(3,33 \%)$ e $G$. crassaformis (1\%). A frequência das espécies Globigerinoides ruber (46,67\%), Globigerina bulloides (9\%) e Globigerinoides saculifer (4,67\%) permanece estável (Figura 2). Os depósitos sedimentares mais recentes na área de estudo estão inseridos na biozona $\mathrm{Z}$.

As espécies do complexo Globorotalia menardii, que vivem nas massas d'água abaixo de $100 \mathrm{~m}$ de profundidade e temperatura de 20,34 à $25,86^{\circ} \mathrm{C}$ (DREFHAL 2011) não foram encontradas. Assim, infere-se que até $100 \mathrm{~m}$ da lâmina d'água a temperatura é maior que $20,5^{\circ} \mathrm{C}$ e abaixo de $100 \mathrm{~m}$ a temperatura é menor que $20^{\circ} \mathrm{C}$, o que permitiu o desenvolvimento de Globorotalia trucatulinoides e G. crassaformis e explica a ausência dos plexos Globorotalia menardii e Pulleniatina nesta faixa de lâmina d'água. Contudo, o limite da zona $\mathrm{Z}$ é marcada no topo do testemunho (amostra 01).

A variação da razão planctônica/bentônica (razão P/B) pode estar relacionada diretamente com o aporte sedimentar e a remobilização do sedimento (SANJINÉS 2006) que, por sua vez, podem ser decorrentes das variações relativas do nível do mar e mudanças climáticas. Apesar de ser identificado um elevado número de espécies planctônicas (acima de 90\%), foi possível realizar a razão P/B, o que resultou no gráfico com duas tendências de queda na frequência bentônica (Figura 3).

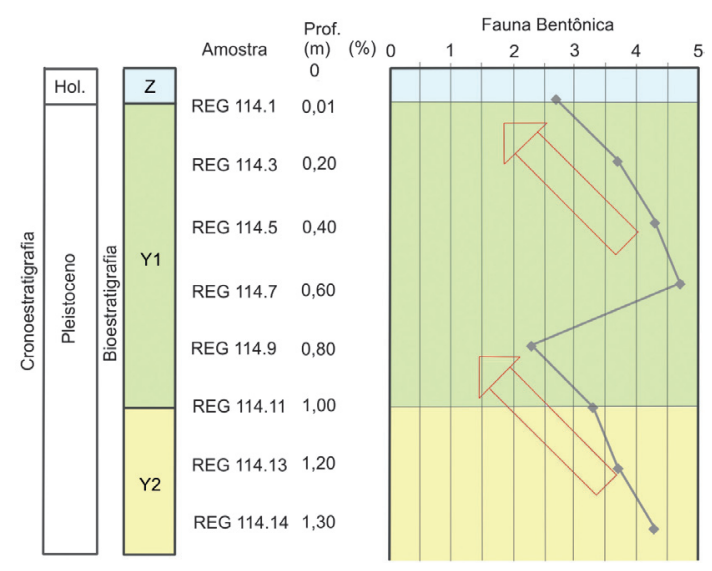

FIGURA 3 - Razão Planctônica/Bentônica para o testemunho REG 114.

A primeira tendência é observada da base do testemunho (amostra 14, 1,30 $\mathrm{m}$ de profundidade) até a amostra 9 ( $0,80 \mathrm{~m}$ de profundidade), onde o percentual de espécies bentônicas diminui gradativamente de $4,3 \%$ para $2,3 \%$. A segunda tendência ocorre na amostra 7 (0,60 $\mathrm{m}$ de profundidade), marcado pelo aumento de espécies bentônicas (de $2,3 \%$ da amostra 09 para $4,7 \%$ na amostra 07 ), seguido por uma nova tendência de queda em dire- 
ção ao topo do testemunho (amostra 1, 0,01 m de profundidade), com variação de $4,7 \%$ para $2,7 \%$ (Figura 3).

Apesar da constatação de duas diminuições acentuadas nos valores de frequência de foraminíferos bentônicos, os baixos valores observados dessa frequência não são suficientes para confirmar a ocorrência de quedas do nível relativo do mar na área em questão.

Apesar da ocorrência de variações climáticas nos períodos Pleistoceno e Holoceno (BARBOSA 2002), não foi possível identificar remobilização de sedimentos do fundo oceânico da área de estudo, visto que ao longo do testemunho não há, aparentemente, mudanças granulométricas significativas e as frequências de foraminíferos planctônicos são, em geral, acima de $90 \%$.

\section{CONCLUSÕES}

No estudo do testemunho REG-114, coletado do sopé continental, foi possível identificar 2400 testas, agrupadas em 35 gêneros ( 28 bentônicas e 7 planctônicas), num total de 63 espécies. A ordem Globigerinina é a principal, representada por 18 espécies.

Os dados de composição de espécies de foraminíferos planctônicos permitiram avaliar as variações da temperatura das águas superficiais na área de estudo. Já o predomínio de sedimentos finos (frações silte e argila) permitiu reconhecer as condições com baixa hidrodinâmica deposicional.

De acordo com a frequência das espécies planctônicas Globigerinoides ruber, G. saculifer, Globigerina bulloides, Globorotalia trucatulinoides e G. crassaformis foi possível sugerir uma bioestratigrafia para o sopé continental ao largo do litoral norte da Bahia. Neste testemunho foi possível identificar os limites das Zonas Y e Z, e das Subzonas Y2 e Y1.

Assim, é possível inferir que o limite entre as Subzonas Y2 e Y1 está marcada em 1,00 m, devido à queda na frequência das espécies Globorotalia trucatulinoides e G. crassaformis (características de água fria) e o rápido aumento da Globigerinoides saculifer (característica de água quente).

O estudo do testemunho REG-114 revelou mais de $90 \%$ de espécies planctônicas, indicando que não houve remobilização do sedimento no fundo marinho. Além disso, não se observou flutuações dos plexos Globorotaria menardii e Pulleniatina, sugerindo não ter havido mudanças significativas em relação ao ambiente na área de estudo desde o Pleistoceno.
Contudo, a variação da razão B/P está relacionada diretamente com o aporte sedimentar e a remobilização do sedimento e, com isso, as análises obtidas dos gráficos não permitem inferir as variações do nível relativo do mar, principalmente por causa das pequenas flutuações das espécies bentônicas.

\section{REFERÊNCIAS BIBLIOGRÁFICAS}

ALVES, R.A. 1999. Estudo Sismoestratigráfico da Bacia do Brasil. Universidade Federal Fluminense, Rio de Janeiro, Dissertação de Mestrado, $119 \mathrm{p}$.

ARAÚJO, T.M.F. 2004. Estudo da Microfauna de Foraminíferos do sedimento da superfície e da subsuperfície da plataforma e do talude continentais da região norte do estado da Bahia (Salvador à Barra do Itariri). Universidade Federal da Bahia, Salvador, Tese de Doutorado, $215 \mathrm{p}$.

ARAÚJO, T.M.F.; MACHADO, A.J. 2008. Benthic foraminifera associated with the South Bahia coral reefs, Brazil. The Journal of Foraminiferal Research, 38: 23-38.

BARBOSA, V.P. 2002. Sistemática, bioestratigrafia e paleoceanografia de foraminíferos do Quaternário do talude continental das bacias de Santos e Campos. Universidade Federal do Rio de Janeiro, Rio de Janeiro, Tese de Doutorado, $455 \mathrm{p}$.

BOLTOVSKY, E.; SCOTT, D.B.; MEDIOLI, F.S. 1991. Morphological variations of benthic foraminiferal test in response to change in ecological parameters: a review. Journal Paleontology, 65: 175-185.

CORLISS, B.H.; FOIS, E. 1990. Morphotype analyses of deep-sea benthic Foraminifera from the Nortwest Gulf of Mexico. Palaios, 5: 589-605.

DAJOZ, R. 1983. Ecologia geral. Vozes, Petrópolis, $4^{\text {a }}$ Ed., 475 p.

DENNE, R.A.; SEN GUPTA, B.K. 1991. Association of bathyal foraminifera with water masses in the northwestern Gulf of Mexico. Marine Micropaleontology,17: 173-193.

DIZ, P.; FRANCÉS, G. 2008. Distribution of live benthic foraminifera in the Ria de Vigo (NW 
Spain). Marine Micropaleontology, 66: 165191.

DREFHAL, M. 2011. Evidências de mudanças paleoclimáticas e paleoceanográficas na costa norte do estado da Bahia durante os últimos 25 mil anos. Universidade Federal da Bahia, Salvador, Dissertação de Mestrado, 205 p.

ERICSSON, D.B.; WOLLIN, G. 1968. Pleistocene climates and chronology in deep-sea sediments. Science, 162 (3859): 1227-1234.

FARIDUDDIN, M.; LOUBERE, P. 1997. The surface ocean productivity response of deeper water benthic foraminifera in the Atlantic Ocean. Marine Micropaleontology, 32, 289-310.

GOODAY, A.J. 2002. Organic-walled allogromiids: aspects of their occurrence, diversity and ecology in marine habitats. The Journal of Foraminiferal Research 32: 384-399.

JOHNSSON, C.C. 1999. Paleoecologia e Bioestratigrafia com base em foraminíferos do Canion Submarino de Salvador-BA. Universidade Federal Fluminense, Niterói, Dissertação de Mestrado, 88 p.

KOWSMANN, R.O.; VICALVI, M.A. 2003. Descrição e datação dos furos da campanha Bucentaur 2003 na área de Jubarte/Cachalote (Bloco BC-60). PDEXP/PETROBRAS (Relatório interno $\mathrm{n}^{\circ} 008 / 2003$ : 17).

MAIA, M.A.M. 2013. Geodiversidade das áreas adjacentes à cadeia submarina de VitóriaTrindade: Construção e aplicação de um modelo de compartimentação em macroescala do assoalho oceânico. Universidade Federal do Rio de Janeiro, Rio de Janeiro, Dissertação de Mestrado, 153 p.

MARTIN, L.; BITTENCOURT, A.C.S.P.; VILASBOAS, G.S.; FLEXOR, J.M. 1980. Mapa geológico do Quaternário costeiro do Estado da Bahia, Escala 1:250.000. Secretaria das Minas e Energia, Governo do Estado da Bahia, Salvador.

NASCIMENTO, H.A. 2003. Análise da fauna de foraminíferos associada aos recifes do extremo sul do estado da Bahia (Corumbau à Nova Viçosa). Instituto de Geociências, Universidade Federal da Bahia, Salvador, Dissertação de Mestrado, 80 p.
d'ORBIGNY. 1826. Ann. Science Natural, ser. 1, 7(26): $273 \mathrm{p}$.

PALMA, J.J.C. 1984. Fisiografia do fundo oceânico. In: C. Schobbenhaus, D.A. Campos, B.R. Derze, H.E. Asmus (eds.) Geologia do Brasil. Rio de Janeiro, DNPM, p. 429-441.

PAWLOWSKI, J., HOLZMANN, M., BERNEY, C., FAHRNI, J., CEDHAGEN, T., BOWSER, S.S. 2002. Phylogenyof allogromiid Foraminifera inferred from SSU rRNA gene sequences. Journal of Foraminiferal Research, 32: 334-343.

PIANNA, B.R. 2010. Padrões de distribuição dos foraminíferos planctônicos no talude continental inferior do Estado da Bahia, Brasil. Universidade Federal da Bahia, Salvador, Monografia de Graduação, 81 p.

RIBEIRO NETO, A.S. 2012. Distribuição vertical da microfauna de foraminíferos em um testemunho da região recifal de abrolhos, sul da Bahia. Cadernos de Geociencias, 9(1): 23-32.

SANJINÉS, A.E.S. 2006. Biocronoestratigrafia e correlação gráfica de três testemunhos a pistão do talude continental da Bacia de Campos, RJ - Brasil. Universidade Federal do Rio de Janeiro, Rio de Janeiro, Dissertação de Mestrado, $212 \mathrm{p}$.

SCHRÖDER, C.J.; SCOTT, D.B.; MEDIOLI, F.S. 1987. Can smaller benthic foraminifera be ignored in paleoenvironmental analyses. Journal of Foraminiferal Research, 10(3): 205-234.

SCOTT, D.B; SCHAFER, C.T.; MEDIOLI, F.S. 2001. Monitoring in coastal environments using foraminifera and thecamoebian indicators. Cambridge University Press, 177 p.

SEN GUPTA, B.K. 1999. Modern Foraminifera. Kluwer Academic Publishers, London, 384 p.

SUGUIO, K. 1992. Dicionário de geologia marinha. Ed. T.A. Queiroz, Salvador, 205 p.

TINOCO, I.M. 1984. Contribuição à metodologia micropaleontológica: qualificação e quantificação dos componentes bióticos dos sedimentos. In: SBG, CONGRESSO BRASILEIRO DE GEOLOGIA, 33, Rio de Janeiro, Anais, 1: 303-311. 
UFKES, E.; JANSEM, S.H.F.; SCHNEIDER, R.R. 2000. Anomalous occurrences of Neoglobloquadrina pachyderma (left) in a 420-KY upwelling Record from Waheis Ridge (SE Atlantic). Marine Micropalentology, 40: 23-42.

VICALVI, M.A., 1999. Zoneamento bioestratigráfico e paleoclimático do Quaternário Superior do talude da Bacia de Campos e Platô de São Paulo adjacente, com base em foraminíferos planctônicos. Universidade Federal do Rio de Janeiro, Rio de Janeiro, Tese de Doutorado, $183 \mathrm{p}$.
VIEIRA, F.S. 2011. Caracterização microbiofaciológica e ambiental com base em foraminíferos bentônicos da plataforma continental da Bacia de Campos, Rio de Janeiro. Universidade Federal da Bahia, Salvador, Tese de Doutorado, $137 \mathrm{p}$.

ZEMBRUSCKI, S.G. 1979. Geomorfologia da margem continental sul brasileira e das bacias oceânicas adjacentes. In: H.A.F. Chaves (ed.) Geomorfologia da margem continental brasileira e das áreas oceânicas adjacentes: relatório final. Rio de Janeiro, PETROBRAS/ CENPES/DINTEP, p. 129-177 (Série Projeto REMAC, 7)

\section{Endereço dos autores:}

Adelino da Silva Ribeiro Neto - Universidade Federal da Bahia, Departamento de Geociências, Av. Adhemar de Barros, 58/405, Ondina, CEP: 40.170-110, Salvador, BA. E-mail: adelinosrn@yahoo.com.br

Tânia Maria Fonseca Araújo - Universidade Federal da Bahia, Departamento de Geociências, Rua Guadalajara, Ed. Simone, 1/301, Morro do Gato, Ondina, CEP: 40140-460, Salvador, BA. E-mail: tfaraujo@, ufba.br

Helisângela Acris Borges de Araújo - Universidade Federal da Bahia, Departamento de Geociências, Av. Miguel Navarro y Canizares, Ed. Serra Atlântica, 400/301, Pituba, CEP: 41810-215, Salvador, BA. E-mail: hacris@ufba.br

Artigo submetido em 30 de dezembro de 2012, aceito em 19 de novembro de 2013. 
